\title{
TWO SHARP INEQUALITIES FOR TRIGONOMETRIC AND HYPERBOLIC FUNCTIONS
}

\section{JÓZSEF SÁNDOR}

Abstract. We determine the best positive constants $p$ and $q$ such that

$$
(\sinh x / x)^{p}<x / \sin x<(\sinh x / x)^{q} .
$$

Some applications for Wilker's type inequalities are given.

Mathematics subject classification (2010): 26D05, 26D07, 26D99. inequalities.

Keywords and phrases: inequalities; trigonometric functions; hyperbolic functions; means and their

\section{REFERENCES}

[1] R. KLÉN, M. VISURI AND M. VuORINEN, On Jordan type inequalities for hyperbolic functions, J. Ineq. Appl., vol. 2010, Article ID 362548, 14 pages.

[2] E. NEUMAN AND J. SÁNDOR, On some inequalities involving trigonometric and hyperbolic functions with emphasis on the Cusa-Huygens, Wilker, and Huygens inequalities, Math. Inequal. Appl. 13, 4 (2010), 715-723.

[3] J. SÁNDOR, On the identric and logarithmic means, Aeq. Math. 40 (1990), 261-270.

[4] H. Alzer, Two inequalities for means, C. R. Math. Rep. Acad. Sci. Canada 9 (1987), 11-16.

[5] J. SÁNDOR, On certain inequalities for means III, Arch. Math. (Basel) 76 (2001), 34-40.

[6] D. S. Mitrinović, Analytic Inequalities, Springer Verlag, 1970. 